\title{
Explaining Showering: a Discussion of the Material, Conventional, and Temporal Dimensions of Practice
}

\author{
by Martin Hand, Elizabeth Shove and Dale Southerton \\ Queen's University; Lancaster University; University of Manchester
}

Sociological Research Online, Volume 10, Issue 2,
< http://mww. socresonline.org.uk/10/2/hand.htm/>
doi:10.5153/sro. 1100

Received: 13 Oct 2004 Accepted: 20 May 2005 Published: 30 Jun 2005

\begin{abstract}
This article considers the increasing popularity of showering in the UK. We use this case as a means of exploring some of the dimensions and dynamics of everyday practice. Drawing upon a range of documentary evidence, we begin by sketching three possible explanations for the current constitution of showering as a private, increasingly resource-intensive routine. We begin by reviewing the changing infrastructural, technological, rhetorical and moral positioning of showering. We then consider how the multiple and contingent constituents of showering are arranged and re-arranged in and through the practice itself. In taking this approach, we address a number of more abstract questions about the relation between practices, technologies and infrastructures and about what these relationships mean for the fixity and fluidity of ordinary routines and for associated patterns of consumption. The result is a method that allows us to analyse the ways in which material cultures and conventions are reproduced and transformed. This has practical implications for those seeking to contain the environmental consequences of resourceintensive practices.
\end{abstract}

\section{Introduction}

1.1 In contemporary Britain it is common to shower once or sometimes twice a day. For many this has become such a normal routine that it is socially and physically uncomfortable to wash any less often. This has not always been so. Less than a generation ago, quite other habits were equally firmly in place. In this paper we consider the transformation of seemingly engrained practices. In particular, we ask how daily showering has taken root so rapidly and how it has become such a necessary part of so many people's lives.

1.2 We focus on showering because this is an area in which new routines have far reaching environmental consequences. Power showers pump out between twenty and fifty litres a minute and with an average showering time of seven to eight minutes, water consumption soon exceeds that of a twice or thrice weekly bath, each bath taking an average of eighty litres of water however long the bather spends (Turton, 1998). There is evidence that people in the UK are showering more than ever before and that they are using more powerful showers (MTP, 2004; Turton, 1998, 1998a; 2001; Shouler et. al. 1997). Industry forecasts currently anticipate a five fold increase in the number of litres used for showering between 1991 and 2021, accompanied by an equally dramatic decline in the use of the bath (Herrington 1996: 35; MTP, 2004). More tangibly, demand for separate shower cubicles has increased at an average of twenty per cent per year since 1999 (BMA, 2004), a figure that suggests the composition of UK bathrooms is on the move and that showering is being positioned as a normal everyday activity.

1.3 Faced with these trends, environmental policy makers have sought to contain consumption through a series of 'technical fixes' - for example, by promoting water metering, advocating low flow shower-heads and labelling appliances (e.g. Turton, 1998a; 2001). While not irrelevant, these initiatives take future demand and consumption as foregone conclusions. Focusing on resources rather than on changing habits, such measures suppose that patterns of unsustainable consumption are the result of information deficit, inappropriate technology or inadequate regulation. This kind of reasoning underpins an environmental policy agenda organised around isolated measures aimed at individual consumers (cf. Daly, 1996; Ekins, 2003; Reisch, 2001; Levett et. al., 2003). As Redclift (1996) points out, environmental policies of this kind routinely take existing commitments and 'ways of life' for granted. As such they take little heed of the sociology of consumption or of those who write about the collective ordering of consumption, the social construction of 'need', or about how practices become 'normal' and how they change (Bourdieu, 1984; Shove \& Warde, 2002; Shove, 2003; Slater, 1997; Southerton et. al. 2004; Warde, 1997). 
1.4 Although few environmentalists would dare question the 'need' for showering, the evolution of routine is a legitimate topic for social science. In analysing the transformation of showering, we hope to show that better understanding of the technological, social and cultural elements that together constitute an apparently necessary daily activity is as important for environmental policy as it is for social theory.

1.5 With this aim in mind, the following account is guided by two questions: first, how might we explain the increasing popularity of showering and especially of power showering in the UK? Second, how has this habit been institutionalised as a normal activity? In reviewing the infrastructural, technological, rhetorical, and moral positioning of showering we engage with a number of more abstract questions about the sociotechnical mediation of domestic practice. Rather than analysing moments of acquisition, or the cultural significance of the specific objects and technologies of showering, we focus on the processes and practicalities of their use. In looking at how complexes of bathroom technology intersect with repertoires of meaning and with conventions of propriety and procedure, and in showing how showering is constituted and reproduced, we extend the reach and scope of what is generally thought of as 'material culture'.

1.6 Our strategy is to begin by outlining three possible explanations of showering's erratic history. How is it that what was a communal/public activity became something to be avoided at all costs, then an infrequent 'luxury' and now an individual and ultimately private routine ${ }^{[1]}$ For the purposes of this article, which is not intended as a definitive 'history of showering', nor as a series of definitive histories, we present each explanatory narrative as a more or less equivalent account. The first relates the routinisation of showering to the development of domestic infrastructures of water and electricity and to associated innovations in bathroom technology. Whatever it's other qualities, this kind of history abstracts the apparatus of showering from the object(s) of showering, namely, bodies and selves. By contrast, the second account explains changing practices of cleansing, restoration, presentation and pleasure in terms of a cultural history of the societal and self-governance of bodies. The third interpretation considers the popularity of showering with reference to the temporal organization of daily life. Here the proposition is that 'speed' and 'convenience' are of defining importance and crucial in explaining both the ascendancy of showering and the decline of bathing.

1.7 In outlining these overlapping, discontinuous and contingent narratives we make an analytic distinction between the material, conventional and temporal dimensions of showering whilst recognizing that the practice involves their simultaneous integration. If we are to explain contemporary forms of showering and their current popularity, we also have to theorize relations between these dimensions and explain how they coalesce at different moments in time. In addressing these issues we seek to develop an account that acknowledges the material, the temporal and the conventional, and that pays due attention to the way in which these dimensions are assembled and integrated in and through practice. This, in turn, raises important questions for environmental policy making in terms of shifting the focus away from resources and toward sociotechnical practices.

\section{Accounting for showering 1: technological innovation}

2.1 The story of how showering has become normal can be told in terms of innovation in plumbing, heating and power. From this point of view, the 'translation' of showering from communal bathing houses, to hydrotherapeutic clinics, to individual homes is only possible because of the construction and availability of specific infrastructural arrangements and material resources.

\section{Piped water and the public-private status of showering}

2.2 The first infrastructures of showering were part of an architecture of public bathing in which the 'showerbath', consisting of a cascade of water falling from an overhead outlet, was distinguished from general bathing in communal pools during the Greco-Roman period (Webb \& Suggitt, 2000). ${ }^{[2]}$ While the Romans introduced many innovations in water engineering, bathing was typically conducted 'in company' and in any event piped water was not routinely provided to private households. In medieval Europe, domestic water supplies were mostly drawn from streams, rivers, wells, and springs. More recently, during the eighteenth and nineteenth centuries, the expansion of urban areas and associated initiatives in sanitary science and engineering brought piped water to public conduits (Webb \& Suggitt, 2000; Wright, 1960). Although piped water supplies were available in the major cities of the UK during 1880s, it was not until the 1930s that middle class homes were routinely equipped with hot and cold running water, and not until the 1950s for the working classes (Hardyment, 1988; Webb \& Suggitt, 2000; Wright, 1960). [3] Though water supplies are important for showering the history of plumbing does not map neatly on to the practice of dousing oneself with water on a daily basis.

2.3 Public bathing as a social ritual all but disappeared in Western Europe after the fall of the Roman Empire. Showering itself vanishes from recorded view through the Middle Ages, a period during which the 
very idea of getting wet was associated with all manner of danger. ${ }^{[4]}$ It was not until the mid-eighteenth century that the first shower patent was granted to an Englishman, William Feetham, in 1767 but in this, as in so many other cases, the availability of a patented technology did not ensure its widespread adoption and use (Webb \& Suggitt, 2000). ${ }^{[5]}$ Such innovations were nonetheless important in distinguishing bathing from showering and in specifying the distinctive hydrotherapeutic properties of the latter (de la Pena, 1999). Two variants emerged: the 'rain bath', involving showering through a rose-head from above, and the 'douchebath' which consisted of the localized application of cold water jets to the body, made possible by the piping of high-pressure water (Webb \& Suggitt, 2000). ${ }^{[6]}$ Although a number of domestic-scale "hand pumped' showers were produced in the 1850s (these circulated a fixed reservoir of water), showering remained a largely non-domestic, collectively organized practice (institutions like the army, for instance, used showering - spraying men with powerful jets of water - as a means of washing as many bodies as possible within a short space of time) until the 1970s.

2.4 In this account, the provision of a reliable domestic water supply is a relevant but not sufficient condition for the privatisation and domestication of showering.

\section{Electrification and instantaneous hot water}

2.5 The electrification of UK homes represents another contributory but still not sufficient step in establishing showering as a normal routine. Electric point-of-use water heaters were both 'safer' and more 'convenient' than the kitchen ranges, coal fired boilers or 'geysers' they replaced. From the 1940s through to the 1960s, the Electrical Development Association (EDA) ${ }^{[7]}$ explicitly promoted the 'immediacy' of electrically powered devices emphasizing this above all other possible 'benefits'. Sure enough, the capacity to heat water relatively quickly and as needed appears to have facilitated the re-framing of bathing and/or showering as a daily rather than weekly activity.

2.6 Together, household plumbing and electricity are important elements in the material configuration of showering as we know it today. While the infrastructural developments described above are undoubtedly significant, they do not in themselves explain changes in shower technology, the increasing popularity of showering (as opposed to bathing) or the development of the 'power shower'.

\section{From hand-pumps to power-showers}

2.7 In many respects the basic design of the shower has changed barely at all over the past 1,000 years. The rose-head device of the Greco-Roman shower-bath remains, in essence, the dominant model for today's devices (Forty, 1986; Webb \& Suggitt, 2000; Wright, 1960). The technological networks into which this simple fitting is located have, however, been subject to radical revision. Rose-head shower fittings were, for instance, augmented with foot-pumps and rubber hoses during the 19th Century, allowing users to experience a continual flow of water as opposed to a one-off downpour from an overhead tank. From the 1870s onwards, more luxurious types of shower co-evolved within the infrastructure of the private bathroom. For example, ornate hooded baths often incorporated elaborate, many jetted shower systems. The majority of these developments were limited to the homes of the elite, and to those already equipped with private bathrooms and piped water. In the early part of the 20th Century the simple overhead shower tank was the most common option - where a shower existed at all - for working and lower middle class households (Webb \& Suggitt, 2000; Wright, 1960). There were few other significant developments until electric wall mounted shower units became available during the 1970s. These were relatively easy to install and were initially viewed as an optional extra - something that might be added over the bathtub without changing either the purpose or the basic architecture of the bathroom. Having acquired a 'foothold' in this manner, the shower has since become a more dominant force within the bathroom environment. During the 1980's and 1990 's, dedicated shower cubicles were included as a regular fixture in new homes and with what we might call the 'hyper-privatisation' of showering, en-suite arrangements have become increasingly popular. ${ }^{[8]}$ Within these dedicated spaces, the power-shower, incorporating a pump to increase the force of the water on the body has come into its own (Shove, 2003; Webb \& Suggitt, 2000). The power-shower, or, more elaborately, the power-hydro-shower, ${ }^{[9]}$ enclosed in its own glass cubicle and located within the en-suite bathroom, represents the latest thing in the world of showering technology.

2.8 In following the infrastructural re-organization of showering from the communal arrangements of antiquity to the hyper-private form that we know today, this first account suggests that showering has been moulded by a series of interdependent technological innovations and market-led imperatives to segment and reinvent. This exclusively materialist narrative has obvious limitations. For example, how is it that although key elements of the infrastructure were in place in the 1950s, sometimes earlier, showers did not became popular until the 1970s? More challenging still, how might we understand the use, the meaning and the significance - not just the availability - of showering technology? 


\section{Accounting for showering 2: the body and the self}

3.1 Our second account explains the changing significance of showering with reference to a cultural history of the body. The guiding assumption here is that different forms of washing are deemed appropriate depending upon whether the body is understood as something requiring 'regeneration' and 'care' (Foucault, 1984; Sennett, 1994); whether it is viewed as a locus of disease requiring protection, monitoring and intervention (cf. Foucault, 1997; Vigarello, 1988), or whether it constitutes a site for multiple, possibly reflexive, modes of self-representation including 'fitness', and continual 'make-over' (Bauman, 2000; Featherstone, 1991, 1995; Giddens, 1991).

3.2 Of course, cultural regimes of the kind listed above do not constitute homogeneous or ready-made bundles of belief and action that people simply absorb. State and government interventions have often been important in establishing the social and cultural dominance of specific understandings of therapy, hygiene, health and the self (Dean, 1999; Foucault, 1997; Rose, 1989, 1999), as have the strategies of companies involved in marketing and commodifying concepts of personal well being and care through continual segmentation (Shove, 2003; Burke, 1996). Having recognized that many actors have a stake in contesting and (re)defining what kinds of bodies should be 'produced' we consider three relatively distinct paradigms regenerating the self, cleanliness and social order, and fit and mobile bodies - each of which have specific implications for bathing and showering.

\section{Regenerating the self}

3.3 In Perikles' Athens, the naked body represented, at least for men, the apex of self-display as civic duty. The exposing of both the body and one's thoughts to others was believed to bind citizens together through mutual 'acts of disclosure' (Sennett, 1994: 33). The practice and physical architecture of public bathing were consequently inseparable, conjoined through ideas about the interior of the body, and its relation to civility and the structure of the city. Foucault $(1984,1997)$ also places the body at the centre of everyday practice. He observes that in Antiquity, 'medicine' (as philosophy) was originally concerned with much more than health, intervention and illness. Rather, medicine defined a way of living involving a reflective mode of relating to oneself, to food, to wakefulness and sleep, and to one's body (Foucault, 1984).

3.4 In later Greco-Roman culture, bathing and showering figured as one element within a broader medical logos - a 'helpful discourse' enabling persons to practice self-care as part of the regimen of everyday life (Foucault, 1984). While bathing/showering was undertaken as communal activity, it was predominately concerned with the well-being of the whole body, hence the recommendation that it should be conducted within public spaces that are 'lofty, well lighted, and as spacious as possible' (Celsus, De Medicina, in Foucault, 1984: 103). This is not to say that all citizens were involved in public bathing in the same way the very wealthy did indeed have private baths, but they also partook in public bathing in order to "curry favour' with their subjects (Sennett, 1994). In sum, communal bathing and showering was central to a process of regeneration in which basically 'fragile bodies' (and corollary civic orders) recovered from the detrimental effects of exposure to an essentially debilitating environment.

\section{Cleanliness and social order}

3.5 One possible explanation for the disappearance of bathing/showering practices between Antiquity and Modernity has to do with changing (Christian) religious and spiritual beliefs about the dangers of 'touching' and getting wet. ${ }^{[10]}$ At the risk of gross over-simplification, we might suggest that the body was (re)constructed as the locus of disease, un-cleanliness, social and moral re-formation. More generally, the individual body became a site of intense therapeutic action, a focus for specific forms of intervention, many of which were linked to emerging but not necessarily consistent discourses of well being, hygiene and cleanliness. ${ }^{[11]}$

3.6 During the nineteenth century, a range of hydrotherapeutic techniques came into vogue, some requiring immersion of the whole body, others subjecting it to precisely targeted jets of water. The practice of what became known as 'taking the cure' (Webb \& Suggitt, 2000; Giedion, 1948) was largely limited to the wealthy middle-classes. Although hydrotherapy represented a form of medicalisation quite unlike that associated with the prevention of disease amongst the lower classes, there are areas of overlap. Most obvious is an association between social status and water, and between washing and respectability. According to Wright (1960) cleanliness was first linked to gentility in the late 19th century. Distinctions between different sectors of society and between more and less 'civilized' nations were drawn in terms of personal hygiene and, as Bushman and Bushman (1998) acknowledge, regular bathing became, and has remained, a requirement for those who want to participate in 'normal' social life. 
3.7 Addressing similar issues but from a different angle, Dean (1999), Foucault (1997) and Rose (1989) argue that over the course of the nineteenth and twentieth centuries, the body (and self) became a primary object of 'government'. Bodies, as constituting the population at large, were taken to be legitimate objects of state intervention, for example, through public health acts and programmes of instruction and advice. Linking these two lines of argument, Forty (1986) suggests that the precise calibration of cleanliness and respectability reflected tensions within a society confronting rapid social change. In this uncertain context, emerging discourses and apparatuses of cleanliness constituted moral technologies - important in distinguishing social classes, 'civilizing' the population, and building national identities (Bushman \& Bushman, 1988; Forty, 1986; Lupton \& Miller, 1992; Shove, 2003; McClintock, 1994).

3.8 Writers like Beck et al. (1994) suggest that the social significance of self-disciplined bodily hygiene has not disappeared but has been re-formulated in terms of the escalating risks of late-modernity. Accordingly, bodies are perceived to be at risk from rogue elements (chemicals, toxins, additives, etc.) and to therefore require continual self-monitoring and maintenance. Though now framed in terms of an increasingly personalized model of responsible agency, the idea of the body as a site of social and moral reform remains important.

\section{Fit and Mobile Bodies}

3.9 It is now hard to imagine that public nakedness might ever constitute evidence of a 'civilized culture' as it did in early Athenian society - yet a number of theorists claim that bodies are again instruments of self-display, albeit in a newly individualized form. In contrast to those who emphasize the social and cultural disciplining of the body, commentators like Bauman (2000), Falk (1994), Featherstone (1991) and Turner (1996) see the 'reflexive' body of late-modernity as a commoditised yet ultimately flexible site of personal re-invention and self-expression. Featherstone (1991), consequently conceptualises dominant images of the body and programmes of body work organized around concepts of fitness, health, lifestyle, freshness, or appearance in terms of a broader framework of 'consumer culture'.

Consumer culture latches onto the prevalent self-preservationist conception of the body, which encourages the individual to adopt instrumental strategies to combat deterioration and decay and combines it with the notion that the body is a vehicle of pleasure and selfexpression (Featherstone, 1991: 170)

3.10 In this analysis, the body is 'released' from the disciplinary technologies of bio-politics. It is accorded the freedom to differentiate and choose between a plethora of activities and to thereby adopt and re-present itself in different guises. Contemporary discourses of the body suggest that it 'requires' a mixture of relaxation and invigoration as well as protection from the circulating risks of techno-science and environmental degradation. Showering occupies a distinctive 'niche' within this complex being distinguished from bathing in terms of the precise action of water on the body and an associated rhetoric of invigoration, freshness and fitness. Showering consequently figures as a form of shock therapy - a wake up call to the body, and an 'alarm clock' rather than a mode of indulgent relaxation. ${ }^{[12]}$

3.11 This second interpretation supposes that dominant images and understandings of the body are internalised and reproduced in the way that people shower and in the meaning and significance accorded to that practice. As indicated above, showering seems to offer qualities and experiences particularly valued in contemporary culture.

\section{Accounting for showering 3: immediacy and convenience}

4.1 A key difference between bathing and showering is that the latter is now associated with speed, immediacy and convenience. In drawing attention to this feature we suggest that it is important to acknowledge the temporal and sequential scheduling of everyday practices and to know where showering and bathing fit in the daily or weekly routine. By definition, collective bathing demands a form of sociotemporal coordination not required of other more privatized arrangements. For other reasons the onceweekly routine of a Sunday bath has given way to a pattern in which there are more but also more fragmented moments of washing. The constant availability of hot water and the valuing of freshness may have something to do with the increasing frequency with which people wash. More generally, it is worth exploring the idea that the popularity of showering relates, again in part, to wider changes in the sociotemporal fabric of daily life.

4.2 There is nothing about the shower that makes it inherently 'quick' though it has often had the potential to be so, especially as compared with bathing. The fact that showering is now valued for its speed and convenience is, however, in keeping with a general societal concern about what has been termed a 'time squeeze' (Demos, 1995; Cross, 1993; Schor, 1992; Hewitt, 1993; Linder, 1970). While there is considerable debate as to whether people actually have less 'free' time now than at points in the past, there is a general 
4.3 An important symptom - and perhaps also a cause - of this sense of 'time squeeze' is the notion that time is a precious commodity that can be organized and managed through the careful sequencing of daily life (Southerton, 2003). According to Hochschild (1997), people in advanced capitalist societies have come to conceive of time in terms of the Taylorised principles of the workplace. Even domestic tasks are broken down into their component parts and (re-)organised to maximize temporal efficiency. As Schwartz-Cowan (1983) describes, labour-saving devices have a part to play in this process and in this ideology. While some devices have made it possible to reduce the amount of time devoted to specific tasks, the frequency with which those tasks are undertaken has often increased. The net result is that temporal schedules are crammed with 'small' moments and episodes of attention. It is in this context that the ability to take a fiveminute shower acquires its appeal. Showering can be slotted into narrow time frames, like those between waking in the morning and leaving for work: time frames from which bathing is excluded. As such the shower belongs to a set of domestic devices whose popularity has grown precisely because they promise to help people cope with the temporal challenges of (late) modern life (Warde, 1999).

4.4 Conceptualising the increasing popularity of showering in these terms is important in that it shows that practices are not held in place by technological or cultural considerations alone. While showering can be a rapid or a drawn out affair, it is only in relation to concerns about a time squeeze that its qualities as a technology of 'convenience' have been understood as such.

\section{Conceptualizing Change}

5.1 In accounting for showering in terms of technological innovation, conceptions of the body and self, and the demands of immediacy and convenience we have presented three separate, if parallel, accounts. Each narrative emphasizes what we might think of as a different aspect or dimension of showering. Since these strands intersect in practice, we now turn our attention to the ways in which they coalesce.

5.2 Looking back, we can discern areas of apparent overlap between the three accounts presented above. For example, where we have communal apparatuses of bathing/showering, we find communally defined bodies that need to 'mutually disclose' their nakedness, or that require 'care' and 'regeneration' in the company of others. Similarly, where we find state investment in the infrastructures and technologies of public health we discover that the individual body is viewed as the site of disease or of social and moral (dis)order. Finally, where we have privatised technologies and cultures of showering so we notice increasingly individualized representations of the body bound up with notions of self-presentation, continual invigoration and 'fitness'. Figure 1 illustrates these 'horizontal' associations. 

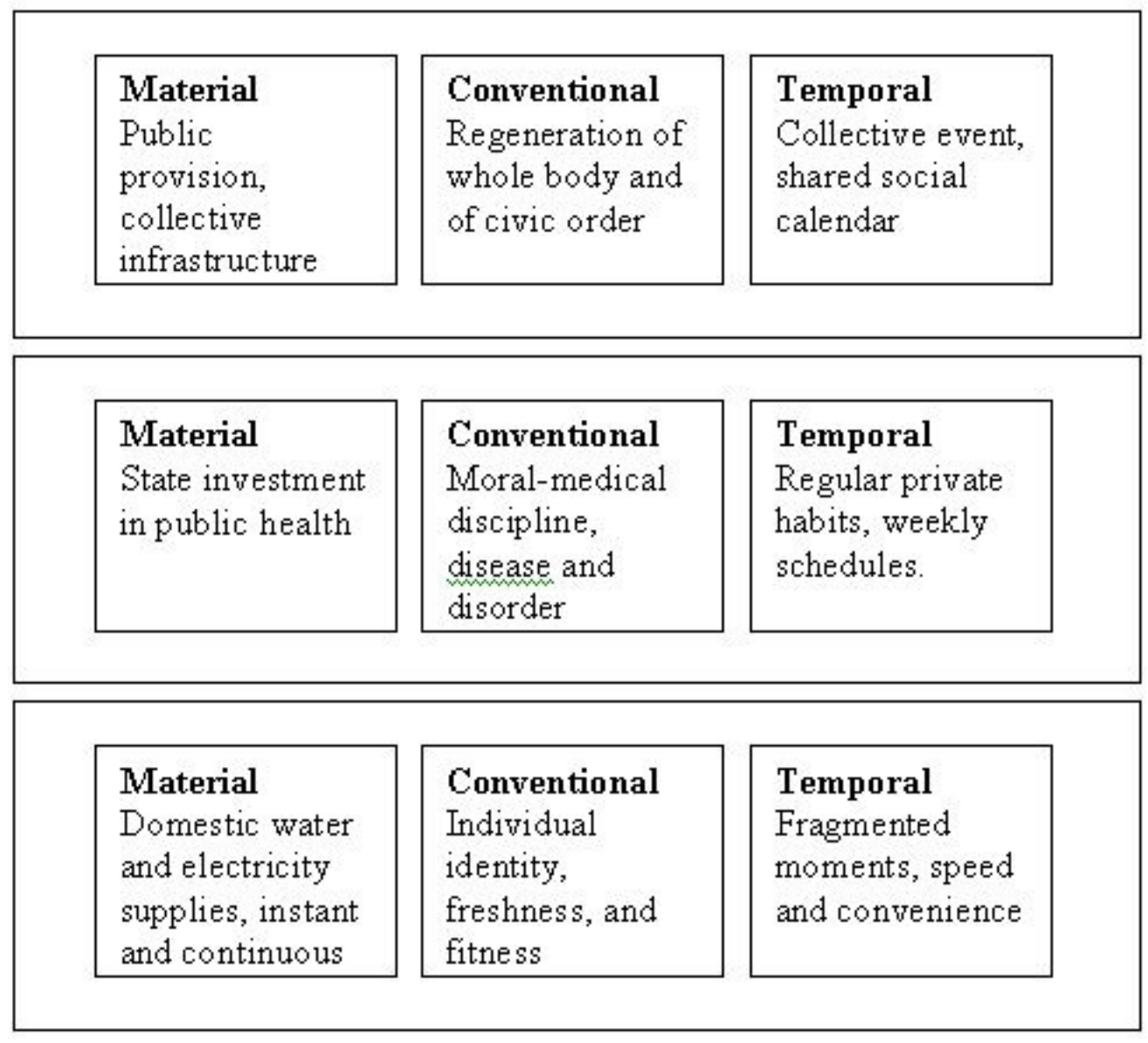

Figure 1. Three configurations of the three dimensions of showering

5.3 Before reading too much into this figure it is important to be clear: we are not suggesting that specific configurations hang together as a matter of necessity. As we have seen, the shower does not depend upon specific forms of plumbing; plumbing does not need to be configured with electricity in order to work; bodies do not need showers to be thought of as clean and although showering is now associated with the notion of convenience, that has not always been so. In other words, the purpose of figure 1 is not to show what 'has to have happened' but to help articulate questions important for an understanding of the material culture of showering and its evolution. In particular, this image prompts us to ask:

- First, how do specific configurations of material infrastructures, conventions and temporal orders actually fit together? What is it that holds the horizontal bands of figure 1 in place? This is in essence a question about order and stability.

- Second, how and why do these configurations change? In one sense there is nothing new about showering but in another, contemporary arrangements are novel in that constituent meanings and technologies have not been brought together in quite this way before.

- Third, and given the historical fluidity of the practice, how is it that daily showering has become so routinised as to appear all but obligatory?

5.4 One method of 'answering' at least the first two questions is to give priority to one or another of the three narratives outlined above. We might therefore offer a dominantly technological or a dominantly conventional history. Alternatively, we might argue contemporary forms of showering are the (inevitable) result of converging material, conventional and temporal conditions.

5.5 Rather than reaching for explanations of this kind, one of the central aims of this paper is to explore the value of conceptualising showering as a form of practice. What does this mean for the terms in which we might analyse and account for its past and present configuration?

5.6 For Reckwitz (2002) and Schatzki (1996), the existence of a practice depends upon the specific interconnectedness of many elements - forms of bodily activities, mental activities, things and their use, background knowledge in the form of understanding, know-how and notions of competence, states of emotion and motivational knowledge. In contrast to much innovation-led work, such an approach requires that we conceptualise materiality, conventionality and temporality in relational and potentially conflictual terms. As a starting point, it demands that we rethink our previous accounts not as distinctive 'histories' or self-standing conceptual orientations but as co-existing arenas within which showering is simultaneously located. These arenas constitute the wider architecture of showering as a particular kind of 'arrangement' 
(cf. Barry, 2001; Deleuze, 1995).

5.7 Figure 2 illustrates this idea and suggests that showering, as practice, is not defined by infrastructural or technological properties, by domestic architectures, or by dominant notions of cleanliness and convenience. Rather, it consists of a specific arrangement of 'elements', the cohesion of which is both constitutive of, and a consequence of, the practice itself. In other words, in accounting for showering, the social, cultural and physical entities gathered under the labels of materiality, conventionality and temporality have no independent existence, none, that is, without the forms of 'know-how', 'competence', and 'ways of doing' that represent and comprise what we currently understand showering to be.
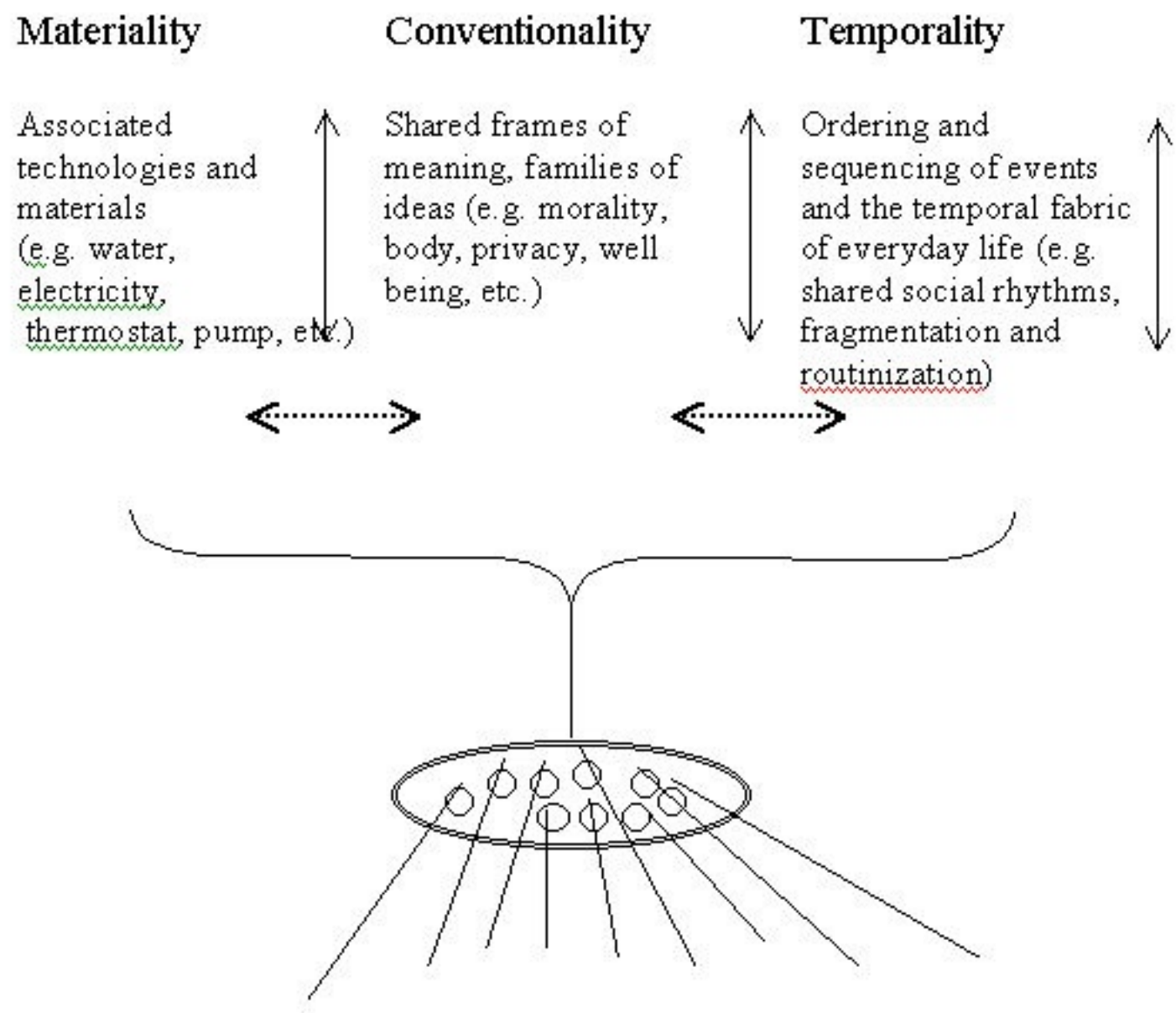

\section{The practice of showering}

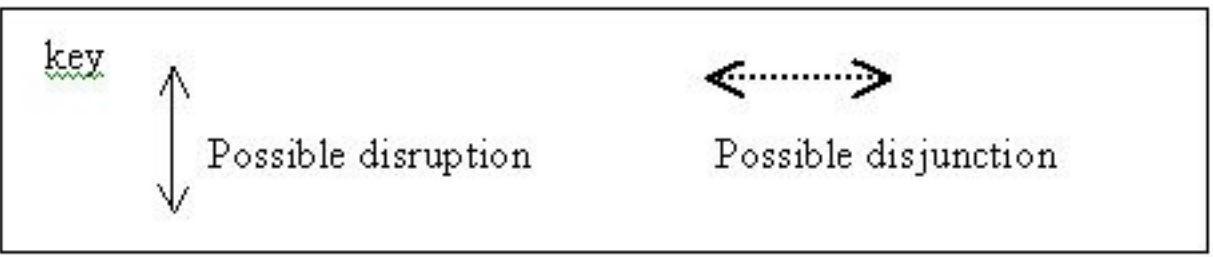

Figure 2. Showering as an integrative practice

5.8 As Figure 2 indicates, showering is constituted and continually re-made through the practice itself. By implication, the future of showering is consequently 'open'. However, this is not entirely true since specific configurations of materiality, conventionality and temporality bring with them different measures of 'closure'. To borrow Bijker's (1992) terminology, 'obdurate' elements have a 'closing' effect on the variety of plausible futures, so structuring otherwise 'open' possibilities. To give just one example, the contemporary bathroom has a social and material form that cuts off some options and avenues and at the same time 'opens' others. Modern shower cubicles are, for example, large enough to allow family members to shower together in ways that were previously impossible. Equally, they are not so large as to permit much more communal forms of bathing. But it is not just technological capacities that 'close' and 'open' possible formulations of showering. The routinisation of the practice - the repeated ways of doing and knowing how to do showering - has a similar effect. In short, habits have a momentum of their own.

5.9 In analysing how and why patterns of showering have changed (and may change in the future) we need 
to look not at one or another part of the picture, but at the arrangement and the relations between the various elements involved. As Barry observes in a different context:

What is inventive is not the novelty of artefacts and devices in themselves, but the novelty of the arrangements with other objects and activities within which artefacts and instruments are situated, and might be situated in the future (Barry, 2001: 212)

5.10 Developing this idea, we suggest that change may occur as a result of disruptions within, and as a consequence of disjunctions between, the dimensions of materiality, conventionality and temporality, all of which are mediated by the practice itself. These possibilities are indicated by the solid vertical arrows (representing disruption within one or another dimension) and by the dashed horizontal arrows (representing disjunction between one or another dimension). While this account gives an impression of an inherently unstable system - unstable in the sense that change in any one 'dimension' has implications for the whole it also underlines the integrative 'work' involved in doing, and thereby stabilizing, showering.

\section{Conclusion}

6.1 This article has explored different ways of conceptualising and explaining the relatively recent emergence of showering as a popular and frequent activity. In the first part we drew upon archive and other material relating to the development of domestic water and electricity supply, to the technology of the bathroom, to changes in the social and cultural significance of the body and to seemingly new forms of temporal order. We used this to construct three partial but plausible ways of accounting for the stops and starts and for the periods of coalescence and fragmentation that characterize the 'story' of showering.

6.2 This exercise generated as many questions as it resolved. In particular it underlined the importance of understanding the relationship between the 'dimensions' represented in each of the three explanatory narratives. In some instances, we observed what seemed to be a relatively tight 'fit'. For example, it is difficult to imagine how contemporary forms of domestic showering might be sustained without reliable supplies of water and electricity. On the other hand, specific meanings of showering - like those associated with morality and propriety - appear to have been in place well before the technological and infrastructural developments associated with the shower's widespread domestication. Similarly, the sociotechnical complex of 'the shower' has continued to evolve within the home even though the cultural significance of showering appears to have stabilized.

6.3 By conceptualising showering as a form of integrative practice we found a way of analysing the dynamics of convention without reifying technological, cultural or social processes. In essence we suggested that it is the practice itself, the doing and 'knowing how to do competently' that provisionally holds the dimensions of materiality, conventionality and temporality together. ${ }^{[13]}$ However, that is only part of the story. Just as practice binds these dimensions in something that resembles a stable form, so it is the media through which change occurs.

6.4 In our opening paragraph we noticed that British people are showering more often than they have ever done before - a trend that has important consequences for present and future patterns of energy and water demand. There is still a long way to go but better understanding of how resource intensive routines come to be as they are, and how they evolve, promises to be of immediate significance for environmental policy. We make some brief observations here.

6.5 Firstly, and most obviously, policy makers need to think about the services that resource consumption makes possible. As we have shown, people do not really 'use' energy or water. Instead, resources are consumed in the course of accomplishing important and valued practices like those of showering, or of heating, cooking, watching television or whatever. Can and even should environmental policy makers seek to shift ordinary routines and taken-for-granted habits? In thinking about this question it is important to realise that many everyday practices are already shaped by state intervention whether through the design and development of supporting infrastructures (including mains water supply), or through more subtle programmes of hygienic discipline and control (Foucault 1977). In acknowledging this point, environmental policy would at least be alert to its own role in sustaining and potentially transforming sociotechnical systems of which the bathroom is a part. Showering routines are not stable: they have changed radically in the past and there is no reason to suppose that current arrangements will last forever. From an environmental point of view, there may well be opportunities to intervene and modify both the process and the outcome of de- and re-routinisation (Elzen et. al. 2004). To take advantage of these or even to identify them requires a different way of thinking about the limits and possibilities of environmental policy.

6.6 Secondly, measures and investments that focus on isolated technological solutions, or that address consumers as equally isolated economic actors are unlikely to have the desired effect. As we and others have observed, devices are appropriated as part of and in relation to existing moral and technological 
landscapes (Silverstone 1993). Again this argues for a more encompassing approach and for one that acknowledges, rather than strips out, the social and material ordering of daily life.

6.7 Thirdly, exhortations to save water or cut back on consumption are unlikely to change or challenge the meaning of showering. In this paper we suggest that conventions of showering are reproduced through the configuration and 'arrangement' of all the elements involved. Practices are not held in place by meaning alone. In this respect, it is relevant to recall our earlier observations about obduracy and inter-dependent path dependencies. Again, the challenge is to recognise and engage with the 'meta-level structuring' of the practice as a whole (Hand and Shove, 2004).

6.8 In conclusion, we have used the case of showering to explore the possibilities and the potential of a 'practice based' approach to the analysis of sociotechnically mediated stability and change. Many questions remain but certain key features have emerged. One is the need to focus on the relation between the material, the conventional and the temporal, as configured through practice. What are the terms and conditions of interdependence and how obdurate are the conventions and habits that arise as a result? Second, and consistent with Giddens' (1984) theory of structuration, it is important to acknowledge and appreciate the reproductive qualities of practice - it is only through practice that ways of understanding and doing are shared and made real. In recognizing that showering is constituted in this way, and in thereby appreciating the fluid and essentially open future of the practice, we suggest that there are more points of leverage and opportunities for intervention than are generally supposed.

6.9 In considering specific mechanisms of change, we suggested that showering habits develop in response to disruption within one or another of the constituent dimensions or because of disjunction between them. But how do forms of disruption and disjunction arise, how do they intersect, and are these the only routes through which new routines take shape? Establishing and institutionalising the capacity to spot such opportunities and take advantage of them - so as to establish, for at least a time, a less resource intensive form of 'normal practice' - is a particularly significant challenge. Much more conceptual and empirical work remains to be done, however this preliminary discussion suggests that the method of putting the practice centre stage provides a novel and useful theoretical framework for examining the current and future dynamics of bathing and showering. In particular, it allows us to develop a more grounded and in a sense a more active understanding of material culture and consumption.

\section{Notes}

1 Our documentary data is drawn from the 'electricity archives' at MMSI, which contain material relating to the Electricity Development Association. We also draw upon material in Good Housekeeping 1922-2002 at the British Library, London. We are grateful to both the British Library and Julie Pedley at the Manchester Museum of Science and Industry for access and assistance.

2 The first forms of bathing are much older. The first recorded bath dates from about 1760 B.C in Crete. It is set in a bathroom with piped water, an arrangement which was to all but disappear in Europe until the nineteenth century. Hence our discussion of the 'emergence of the bathroom' should be seen in the context of the 'modern bathroom' (Wright 1960).

3 This is despite the fact that most of the new suburban developments built during the 1920's and 1930's were equipped with hot and cold water.

${ }^{4}$ According to Vigarello (1988), it was common to believe the skin to be porous. Immersion in water might therefore allow important bodily fluids to 'leak out' and potentially harmful substances to leak in.

${ }^{5}$ In this case, the existence of a patented shower did not precipitate the sudden or widespread adoption of showering. A host of other social and technical 'elements' needed to be in place.

${ }^{6}$ The army also used the shower as a means of washing as many bodies as possible within the shortest space of time. Men were sprayed with a jet of water - initially experienced as a collectively organized practice.

7 The Electrical Development Association was founded under the Electricity Act of 1919, and funded by the supply undertakings. From 1926 onwards, the development of domestic demand was a key concern of the EDA. See Forty, 1986.

8 The en-suite bathroom was a common feature of American hotels during the early 20th Century, and appears to have become associated with a particular kind of luxury in the home (Webb \& Suggitt, 2000). 
${ }^{9}$ These many jetted fibreglass cousins of some of the earliest hydrotherapeutic models to be found in the luxury homes of the 1880s, now include 'plumbed in' radio and telephone systems, seats, aromatherapy equipment, and remote controls.

10 These ideas also relate to theories about the transmission of disease - in particular, the plague.

11 This conception of the body or self as an object of therapy is not limited to notions of hygiene. The emerging disciplines of the human sciences are instrumental in constructing the body (and soul) as something to be analyzed, treated, reformed, and cured. The idea of hydrotherapy, framing the reemergence of showering, should be seen in this broader context of subjectification. For the exemplary account, see Rose, 1999 [1989].

12 Though notice the introduction of seats in the latest hydro-showers. In conjunction with the development of built-in facilities for aroma therapy these imply a more relaxed mode of showering.

13 If the practice of showering is removed from the equation (i.e. from Figure 2) then all that remains are sets of abstractions. These are the traditional 'objects' of environmental policy.

\section{References}

BATHROOM MANUFACTURERS ASSOCIATION, Market Trends Report, August 2004. BMA: Stoke-onTrent.

BAUMAN, Z. (2000) Liquid Modernity. Cambridge: Polity Press.

BARRY, A. (2001) Political Machines. London: Athlone Press.

BECK, U, Giddens, A, Lash, S. (1994) Reflexive Modernization. Cambridge: Polity Press

BIJKER, W. (1992) 'The social construction of fluorescent lighting, or how an artifact was invented in its diffusion stage', in Bijker, W. and Law, J. (eds.) Shaping Technology, Building Society, Cambridge MA, MIT Press.

BOURDIEU, P. (1984) Distinction: a social critique of judgement and taste . London: Routledge.

BURKE, T. (1996) Lifebuoy Men, Lux Women: Commodification, consumption and cleanliness in modern Zimbabwe. London: Leicester University Press.

BUSHMAN, R. and Bushman, C. (1988) 'The early history of cleanliness in America', Journal of American History, 74(4): 1213-38.

CROSS, G. (1993) Time and Money - The Making of Consumer Culture . Routledge.

DALY, H. (1996) Beyond Growth: The Economics of Sustainable Development . Boston, MA: Beacon Press.

DEAN, M. (1999) Governmentality. London: Sage.

DE LA PEÑA, 1999) C. (1999) 'Recharging at the Fordyce: confronting the machine and nature in the modern bath', Technology and Culture, 40(4): 746-69

DEMOS (1995) The Time Squeeze. London: Demos.

EKINS, P. (2003) 'Environment and human behaviour: a new opportunities programme, available at: http://www.psi.org.uk/ehb/, $13^{\text {th }}$ August, 2004.

ELZEN, B. Geels, F. G. and Green, K. (eds.) (2004) System Innovation and the Transition to Sustainability: Theory, Evidence and Policy. Cheltenham: Edward Elgar.

FALK, P (1994) The Consuming Body. London: Sage.

FEATHERSTONE, M. (ed.) (1991) The Body: Social Process and Cultural Theory . London: Sage.

FEATHERSTONE, M. (1995) Undoing Culture: Globalization, Postmodernism, and Identity. London: Sage.

FORTY, A. (1986) Objects of Desire. London: Thames \& Hudson. 
FOUCAULT, M. (1984) History of Sexuality 3: Care of the Self . London: Penguin.

FOUCAULT, M. (1997) Ethics: The Essential Works Vol. 3. London: Penguin.

FOUCAULT, M. (1977) Discipline and Punish. London: Penguin.

GIDDENS, A. (1991) The Consequences of Modernity. Stanford University Press.

GIEDION S. (1948) Mechanisation Takes Command: A contribution to anonymous history. New York: W W Norton.

HARDYMENT, C. (1988) From Mangle to Microwave: The Mechanization of Household Work . Cambridge: Polity Press.

HERRINGTON, P. (1996) Climate Change and the Demand for Water . London: HMSO.

HEWITT, P. (1993) About Time: the revolution in work and family life. Rivers Oram Press.

HOCHSCHILD, A. R. (1997) The Time Bind: when home becomes work and work becomes home. CA Henry Holt.

LEETE, L. \& Schor, J. (1994) Assessing the Time Squeeze Hypothesis: Estimates of Market and NonMarket Hours in the United States, 1969-1989. Industrial Relations, 33(1): 25-43.

LEVETT, R. Christie, I. Jacobs, M. Therivel, R. (2003) A Better Choice of Choice: Quality of Life, Consumption and Economic Growth. London: Fabian Society Report.

LINDER, S. B. (1970) The Harried Leisure Class. Columbia University Press.

LUPTON, E. and Miller, J. (1992) The Bathroom, the Kitchen and the Aesthetics of Waste: A process of elimination. New York: Kiosk.

MCCLINTOCK, A. (1994) 'Soft-Soaping empire: commodity racism and imperial advertising' in Robertson, G. (ed.), Travellers Tales, London: Routledge.

MARKET TRANSFORMATION PROGRAMME, Policy Brief on UK Domestic Showers . Didcot. 24 September, 2004.

RECKWITZ, A. (2002) 'Toward a theory of social practices: a development in culturalist theorizing', European Journal of Social Theory, 5(2): 243-63.

REDCLIFT, M. (1996) Wasted: Counting the Costs of Global Consumption . London: Earthscan.

REISCH, L. (2001) 'Time and Wealth: the role of time and temporalities for sustainable patterns of consumption', Time and Society, 10 (2/3), 387-405.

ROSE, N. (1989) Governing the Soul: The Shaping of the Private Self . London: Free Association Books.

ROSE, N. (1999) Powers of Freedom: Reframing Political Thought . Cambridge: Cambridge University Press

SCHATZKI, T. (1996) Social Practices: a Wittgensteinian approach to human activity and the social. Cambridge: Cambridge University Press.

SCHWARTZ-COWAN, R. (1983) More Work for Mother: the ironies of household technology from the open hearth to the microwave. Basic Books.

SENNETT, R. (1994) Flesh and Stone: the body and the city in western civilization. London: Faber \& Faber.

SHOULER, M., Pitts, N., Thomas, F., and Hall, J. (1997) Water Conservation: Shower evaluation. BRE Report No CR 164/97, Watford: Building Research Establishment.

SHOVE, E. (2003) Comfort, Cleanliness and Convenience: The social organization of normality. London: Berg

SHOVE, E. Warde, A. (2002) 'Inconspicuous Consumption: the sociology of consumption, lifestyles and the environment, in Dunlap, R. Buttel, F, Dickens, P. Gijswijt, A. (eds.) Sociological Theory and the 
Environment: Classical Foundations, Contemporary Insights. Lanham, MA: Rowman and Littlefield.

SILVERSTONE, R. (1993), 'Time, information and communication technologies and the household', Time and Society 2(3): 283-311.

SLATER, D. (1997) Consumer Culture and Modernity . Cambridge: Polity Press.

SOUTHERTON, D. (2003) 'Squeezing Time': allocating practices, co-ordinating networks and scheduling society', Time \& Society, 12(1): 5-25

SOUTHERTON, D. \& Tomlinson, M. (2003) "'Pressed for Time" - the differential impacts of a "time squeeze"'. CRIC Discussion Paper No 60, The University of Manchester \& UMIST.

TURNER, B. (1996) The Body and Social Theory . London: Sage.

TURTON, P. (1998) 'The UK Experience', presentation at CIWEM Water Conservation and Re-use Seminar, February 1998, CIWEM.

TURTON, P. (1998a) 'The Ideal Conservation Home', Demand Management Bulletin. London: Environment Agency.

TURTON, P. (2001) 'Scottish PCC Study, Demand Management Bulletin. London: Environment Agency.

VIGARELLO, G. (1988) Concepts of Cleanliness: Changing Attitudes in France Since the Middle Ages . Cambridge: Cambridge University Press.

WARDE, A. (1997) Consumption, Food and Taste. Cambridge: Polity.

WARDE, A. (1999) Convenience food: space and timing. British Food Journal, 101(7): 518-27.

WEBB, P. Suggitt, S. (2000) Gadgets and Necessities: An Encyclopaedia of Household Innovations. London: ABC-CLIO.

WRIGHT, L. (1960) Clean and Decent. London: Penguin. 